\title{
Substituent Effect on Oxidative Decomposition of Acylferrocenes
}

\author{
Yutaka Okada ${ }^{1}$, Motoi Sakai ${ }^{1}$ \\ ${ }^{1}$ Department of Applited Chemistry, Ritsumeikan University, Kusatsu, Japan \\ Correspondence: Yutaka Okada, Department of Applited Chemistry, Ritsumeikan University, Kusatsu, 5258577, Japan. \\ E-mail: ygvictor@sk.ritsumei.ac.jp
}

Received: April 8, 2019 Accepted: May 15, 2019 Online Published: May 19, 2019

doi:10.5539/ijc.v11n2p31 URL: https://doi.org/10.5539/ijc.v11n2p31

\begin{abstract}
Acylferrocenes are oxidized by iron(III) chloride in methanol and then immediately decomposed. In this study, the oxidative decomposition of some alkanoyl- and aroylferrocenes was performed and the substituent effect on the reaction rate was investigated. It was found that the reaction was governed by the accessibility of the oxidizing agent to the iron atom and the degree of electron-withdrawing effect of the carbonyl group towards the ferrocene nucleus.
\end{abstract}

Keywords: acylferrocenes, oxidation, decomposition, iron(III) chloride, substituent effect

\section{Introduction}

In recent years, ferrocenes have been extensively studied as catalysts in asymmetric synthesis and as functional materials (Zora, Kokturk, \& Eralp, 2006)(Zora, Tumay, \& Bueyuekguengoer, 2007). Although the ferrocene moiety is thermally stable, it is unstable towards oxidation. It is therefore useful to accumulate knowledge about the oxidative reactivity of ferrocenes. However, most of the oxidation reactions of ferrocenes reported thus far are electrochemical in nature (Bahadori, Abdul Manan, Chakrabarti, Hashim, Mjalli, Al Nashef, Hussain, \& Low, 2013) (Hosseini, Collman, Devadoss, Williams, Barile, \& Eberspacher, 2010) (Palmer, Liu, Kung, Hod, Farha, \& Hupp, 2018), and there are very few reports on their chemical oxidation (Hayashi, \& Okada, 1995) (Hayashi, Okada, \& Hukuchi, 1994) (Okada, \& Hayashi, 1989) (Okada, Nakagawa, \& Hayashi, 2001).

Ferrocene is very stable in air, and its oxidation from the Fe(II) state to $\mathrm{Fe}(\mathrm{III})$ hardly occurs. However, under acidic conditions, it is easily oxidized in air, resulting in a blue-colored ferrocenium ion. Oxidative decomposition of alkylferrocenes under acidic conditions is reported in the literature (Hayashi, Okada, \& Hukuchi, 1994). When alkyl ferrocenes are reacted in 1,2-dichloroethane in the presence of trichloroacetic acid, the color of the reaction solution changes from yellow to blue, indicating the generation of the ferrocenium ion (Scheme 1 (a)). However, when acylferrocenes are reacted in methanol under the same conditions, the color of the reaction solution changes to pale purple, rather than blue, indicating that this reaction proceeds via a mechanism different from that in the earlier case (Okada, \& Hayashi, 1989). Acylferrocenes undergo oxidative decomposition via a two-step mechanism in the presence of trichloroacetic acid in methanol. In the first step, coordination of the acidic proton to the carbonyl oxygen of acylferrocene produces an $\alpha$-carbocation. During the generation of ferrocenium ions from acylferrocenes, the $\pi$-electron density of the cyclopentadienyl ring decreases due to the electron-withdrawing effect of the acyl group, thereby decreasing the electron density of the iron atom. Therefore, the ferrocenium ion gets easily decomposed and $\mathrm{Fe}^{3+}$ is generated. In the second step, $\mathrm{Fe}^{3+}$, which is a strong oxidizing agent, oxidizes the iron atom in the ferrocene nucleus. In other words, this step is the oxidation reaction of ferrocenes by $\mathrm{Fe}^{3+}$ (Scheme 1(b)). In this step, the ferrocene nucleus decomposes, so that the intensity of the fourth band absorption decreases (Scheme 2) (Hayashi, Okada, \& Hukuchi, 1994).

Factors affecting the rate of the first step of this reaction have been studied mainly from the viewpoint of stabilization of the $\alpha$-carbocation (Muther, Frohlich, Muck-Lichtenfeld, Grimme, \& Oestreich 2011). However, factors affecting the rate of the second step are hardly elucidated. Therefore, in this study, the oxidation reaction of some alkanoyl- and aroylferrocenes (Scheme 1) by iron(III) chloride was carried out and the relationship between the reaction rate and the nature of substituents present in ferrocenes was examined.

\section{Method}

All reagents were of commercial quality (from Nacalai Tesque, Inc., Japan and Wako Pure Chemical Industries Co., Japan) and were used as received. 


\subsection{Synthesis}

All the ferrocenes used in this study were synthesized by well-known methods (Hayashi, \& Okada, 1995).

\subsection{Oxidation Reaction}

One of the mentioned acylferrocenes $\left(4.2 \times 10^{-5} \mathrm{~mol}\right)$ and $50 \mathrm{~mL}$ of methanol were charged into a three-necked round-bottomed flask, and $0.017 \mathrm{~g}\left(1.0 \times 10^{-4} \mathrm{~mol}\right)$ of iron(III) chloride, dissolved in $10 \mathrm{~mL}$ of methanol, was added to it from a dropping funnel. After stirring the reaction mixture in air for $1 \mathrm{~min}$, the resultant solution was placed in a lidded UV cell whose internal temperature was maintained at $40^{\circ} \mathrm{C}$. The decomposition reaction was tracked by monitoring the changes in the absorbance of the solution at the wavelength corresponding to the fourth absorption band of the UV spectrum.

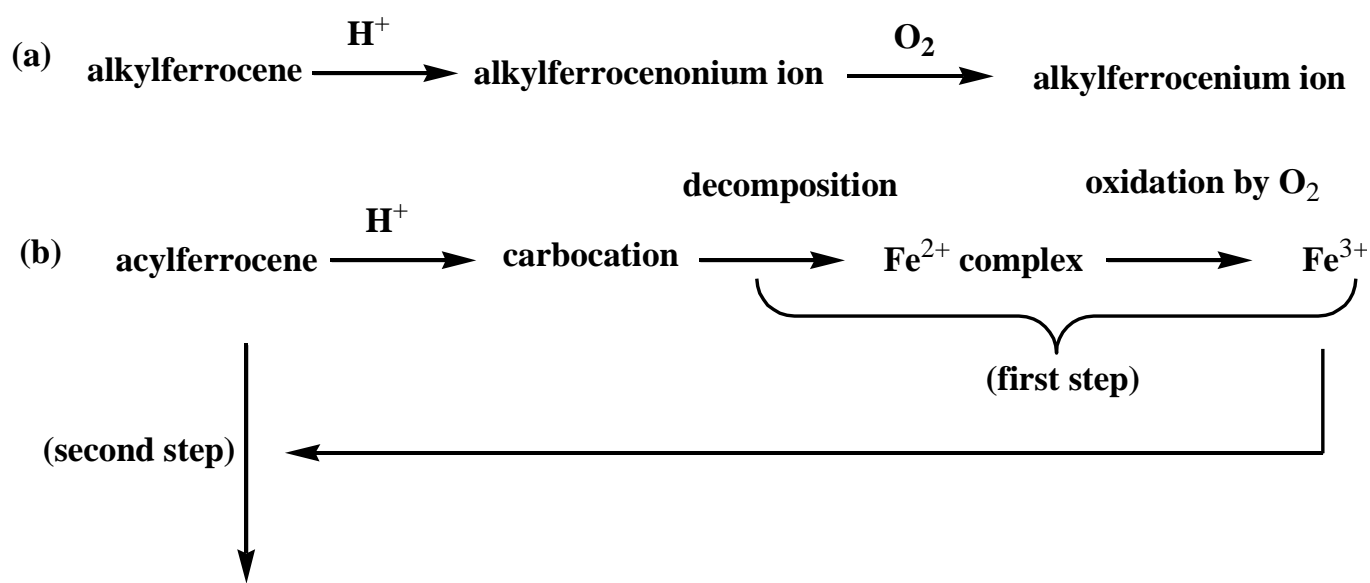

Scheme 1. Oxidation reaction of (a) alkylferrocenes and (b) acylferrocenes

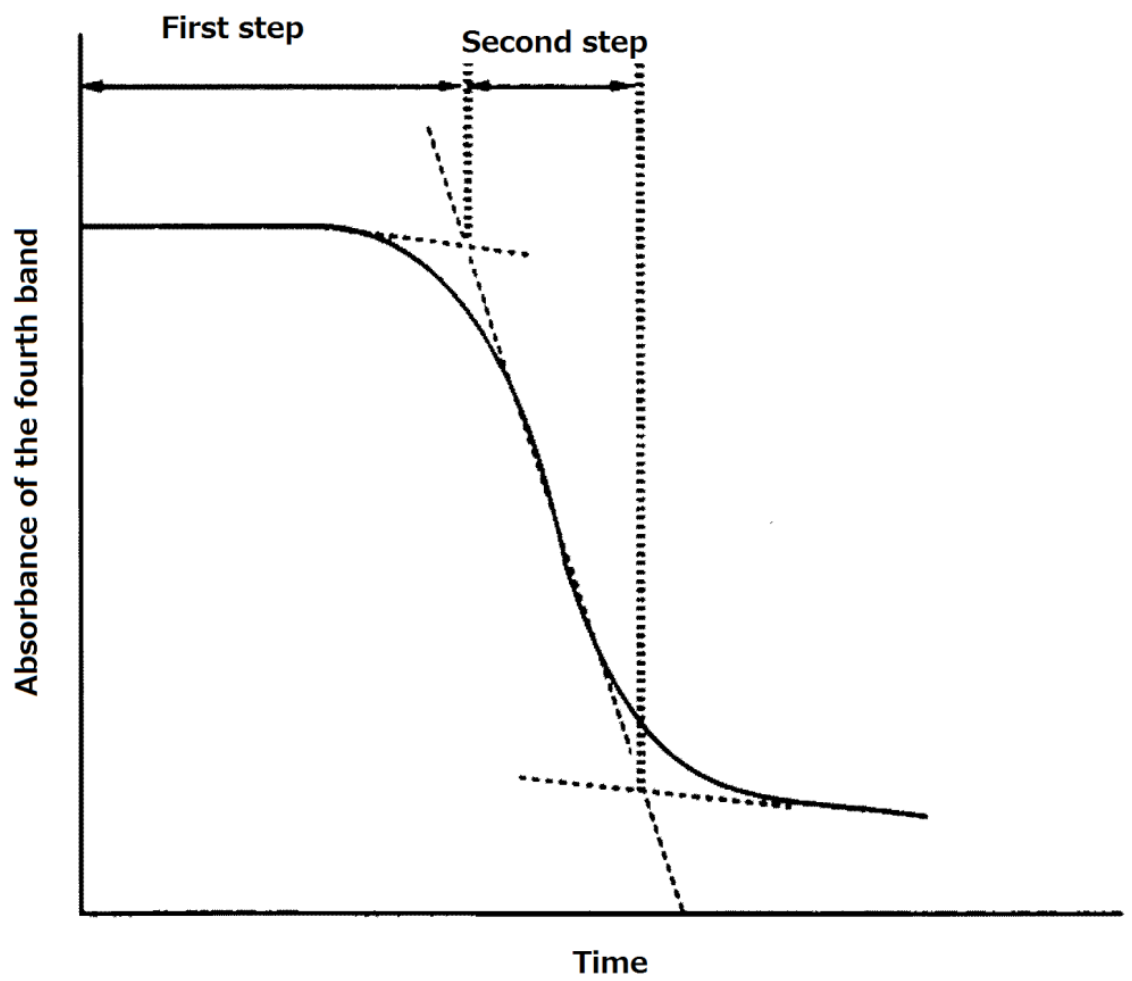

Scheme 2. Schematic presentation of the change of the fourth band absorbance in the cource of the decomposition reaction of acylferrocenes (Hayashi, Okada, \& Hukuchi, 1994) 


\section{Results and Discussion}

Table 1 shows the rate constants of the oxidative decomposition reaction of acylferrocenes.

\subsection{Alkanoylferrocenes}

As shown in Table 1, the rate of oxidative decomposition of acetylferrocene (Entry 1) is slightly faster, while those of (2-methylpropanoyl)-, (2,2-dimethylpropanoyl)-, and (3,3- dimethylbutanoyl)ferrocenes (Entries 3, 4, and 6) were very slow.

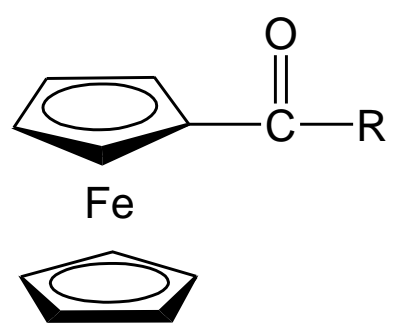

$$
\begin{aligned}
& \mathbf{R}=\mathrm{CH}_{3}^{-} \\
& \mathbf{R}=\mathrm{CH}_{3} \mathrm{CH}_{2^{-}} \\
& \mathbf{R}=\left(\mathrm{CH}_{3}\right)_{2} \mathrm{CH}^{-} \\
& \mathbf{R}=\left(\mathrm{CH}_{3}\right)_{3} \mathrm{C}- \\
& \mathbf{R}=\mathrm{CH}_{3} \mathrm{CH}_{2} \mathrm{CH}_{2^{-}} \\
& \mathbf{R}=\left(\mathrm{CH}_{3}\right)_{3} \mathrm{CCH}_{2^{-}} \\
& \mathbf{R}=\mathrm{CH}_{3}\left(\mathrm{CH}_{2}\right)_{3^{-}} \\
& \mathbf{R}=\mathrm{CH}_{3}\left(\mathrm{CH}_{2}\right)_{4^{-}} \\
& \mathbf{R}=\mathrm{CH}_{3}\left(\mathrm{CH}_{2}\right)_{6^{-}} \\
& \mathbf{R}=\mathrm{CH}_{3}\left(\mathrm{CH}_{2}\right)_{8^{-}} \\
& \mathbf{R}=\mathrm{CH}_{3}\left(\mathrm{CH}_{2}\right)_{12^{-}} \\
& \mathbf{R}=\mathrm{CH}_{3}\left(\mathrm{CH}_{2}\right)_{14^{-}} \\
& \mathbf{R}=\mathrm{CH}_{3}\left(\mathrm{CH}_{2}\right)_{16^{-}}
\end{aligned}
$$

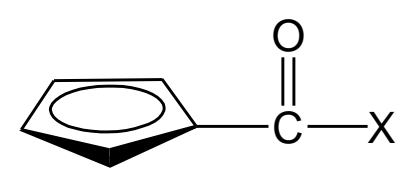

$\mathrm{Fe}$

$$
\begin{aligned}
& \mathrm{X}=\text { phenyl- } \\
& \mathrm{X}=2-\mathrm{CH}_{3} \text { phenyl- } \\
& \mathrm{X}=4-\mathrm{CH}_{3} \text { phenyl- } \\
& \mathrm{X}=2,4,6-\text { tri } \mathrm{CH}_{3} \text { phenyl- } \\
& \mathrm{X}=1 \text {-naphthyl- } \\
& \mathrm{X}=2-\text { naphthyl- } \\
& \mathrm{X}=4-\mathrm{CH}_{3} \mathrm{O} \text { phenyl- } \\
& \mathrm{X}=4-\left(\mathrm{CH}_{3} \mathrm{OCO}\right) \text { phenyl- }
\end{aligned}
$$

Scheme 3. Structure of acylferrocenes

It is understood that the three alkanoylferrocenes with slow reaction rates have a structure branched either at the $\alpha$-position or the $\beta$-position. The oxidative decomposition reaction of acylferrocenes carried out in this study is an oxidation reaction triggered by $\mathrm{Fe}^{3+}$ as described in the introduction. That is, $\mathrm{Fe}^{3+}$ attacks and oxidizes the iron atom in the ferrocene nucleus, so that the decomposition reaction is induced. Therefore, with regard to the attack on the iron atom in the ferrocene nucleus by $\mathrm{Fe}^{3+}$, it is presumed that the attack is suppressed when the periphery of the iron atom of ferrocene is sterically crowded. It is considered that although the attack by $\mathrm{Fe}^{3+}$ from the opposite side of the substituent is not prevented, the overall probability of the attack is less when compared to that in the molecule in which the neighborhood of the iron atom is not crowded. Hence, the rate of oxidative decomposition of (2-methylpropanoyl)-, (2,2-dimethylpropanoyl)-, and (3,3-dimethylbutanoyl) ferrocenes is slow due to the steric hindrance imparted by such bulky substituents around the Fe atom.

\subsection{Aroylferrocenes}

\subsubsection{Electronic Effect by Substituent}

The reaction rates of benzoyl-, (4-methylbenzoyl)-, (4-methoxybenzoyl)-, and [4-(methoxycarbonyl)benzoyl]ferrocene (Entries 14, 16, 20, and 21) were compared. The decomposition of [4-(methoxycarbonyl)benzoyl]ferrocene, with a strong electron-withdrawing group, was the slowest, followed by that of benzoylferrocene and (4-methylbenzoyl)ferrocene, which bear the weak electron-donating groups, while that of (4-methoxybenzoyl) ferrocene, with a strong electron-donating group, was the fastest. The influence of the electronic effect by these substituents on the reaction rate was inferred as follows.

In the case of [4-(methoxycarbonyl)benzoyl]ferrocene, the induction effect of the electron-withdrawing carbonyl group 
on the cyclopentadienyl group is further enhanced by the strong electron-withdrawing property of the methoxycarbonyl group substituted at the 4-position. Therefore, the electron density in the ferrocene nucleus is lower than that in the case of other aroylferrocenes. Therefore, the attack on the iron atom in the ferrocene nucleus by $\mathrm{Fe}^{3+}$ would be suppressed and the reaction rate would be slow. Conversely, in (4-methoxybenzoyl)ferrocene, since the methoxy group is a strong electron-donating group, the electron density at the ferrocene nucleus becomes higher than in other aroylferrocenes. Therefore, it was inferred that the rate of oxidative decomposition increased.

Table 1. Wave length of the fourth absorption band and kinetic constants of oxidative decomposition

\begin{tabular}{|c|c|c|c|}
\hline Entry & Compound & $\begin{array}{l}\text { Wave length of the } \\
\text { fourth absorption band } \\
(\mathrm{nm})\end{array}$ & $k\left(\times 10^{3} \sec ^{-1}\right)$ \\
\hline 1 & acetylferrocene & 458.5 & 4.7 \\
\hline 2 & propanoylferrocene & 455.5 & 4.4 \\
\hline 3 & (2-methylpropanoyl)ferrocene & 457.0 & 3.1 \\
\hline 4 & (2,2-dimethylpropanoyl)ferrocene & 459.5 & 2.2 \\
\hline 5 & butanoylferrocene & 456.5 & 4.2 \\
\hline 6 & (3,3-dimethylbutanoyl)ferrocene & 461.0 & 3.2 \\
\hline 7 & pentanoylferrocene & 456.0 & 4.0 \\
\hline 8 & hexanoylferrocene & 458.0 & 4.2 \\
\hline 9 & octanoylferrocene & 459.5 & 4.1 \\
\hline 10 & decanoylferrocene & 457.0 & 4.3 \\
\hline 11 & tetradecanoylferrocene & 457.0 & 4.3 \\
\hline 12 & heptadecanoylferrocene & 457.5 & 4.4 \\
\hline 13 & ocatadecanoylferrocene & 456.5 & 4.3 \\
\hline 14 & benzoylferrocene & 483.0 & 5.0 \\
\hline 15 & (2-methylbenzoyl)ferrocene & 479.5 & 5.6 \\
\hline 16 & (4-methylbenzoyl)ferrocene & 480.5 & 5.2 \\
\hline 17 & (2,4,6-trimethylbenzoyl)ferrocene & 481.5 & 6.3 \\
\hline 18 & 1-naphthoylferrocene & 485.0 & 5.6 \\
\hline 19 & 2-naphthoylferrocene & 486.5 & 4.9 \\
\hline 20 & (4-methoxybenzoyl)ferrocene & 478.5 & 6.1 \\
\hline 21 & [4-(methoxycarbonyl)benzoyl]ferrocene & 494.5 & 3.7 \\
\hline
\end{tabular}

The relationship between the Hammett's substituent constant ( $\sigma)(\mathrm{Jaffe}, 1953)$ and the reaction rate constant $(k)$ is shown in Fig. 1. Since a linear relationship can be seen, it can be concluded that the electronic effect by the above-mentioned substituents greatly influences the reaction rate.

\subsubsection{Twisting Effect by Substituent}

The rates of decomposition of (2-methylbenzoyl)ferrocene and (4-methylbenzoyl)ferrocene (Entries 15 and 16, respectively), and 1- and 2-naphthoylferrocenes (Entries 18 and 19, respectively) were compared. It was found that the reaction rates of (2-methylbenzoyl)ferrocene and 1-naphthoylferrocene were faster than those of (4-methylbenzoyl)ferrocene and 2-naphthoylferrocene, respectively.

Next, the molecular structure of (2-methylbenzoyl)ferrocene and 1-naphthoylferrocene was noticed. It is known that the phenyl groups in benzophenone are twisted with respect to each other due to steric hindrance (Kokesh, \& Hall, 1975). It is considered that such twist might exist in benzoylferrocene too. Furthermore, it is considered that the twisting between the substituent and the cyclopentadienyl group is larger in sterically bulky (2-methylbenzoyl)ferrocene and 
1-naphthoylferrocene. However, in the case of (4-methylbenzoyl)ferrocene and 2-naphthoylferrocene, the degree of such twist is considered to be smaller because of no substituents near the carbonyl group. In (2-methylbenzoyl)ferrocene and 1-naphthoylferrocene, since the corresponding substituents and the cyclopentadienyl groups are twisted at an angle, the electron-withdrawing effect of the carbonyl group on the ferrocene nucleus becomes small and the reaction rate decreases.

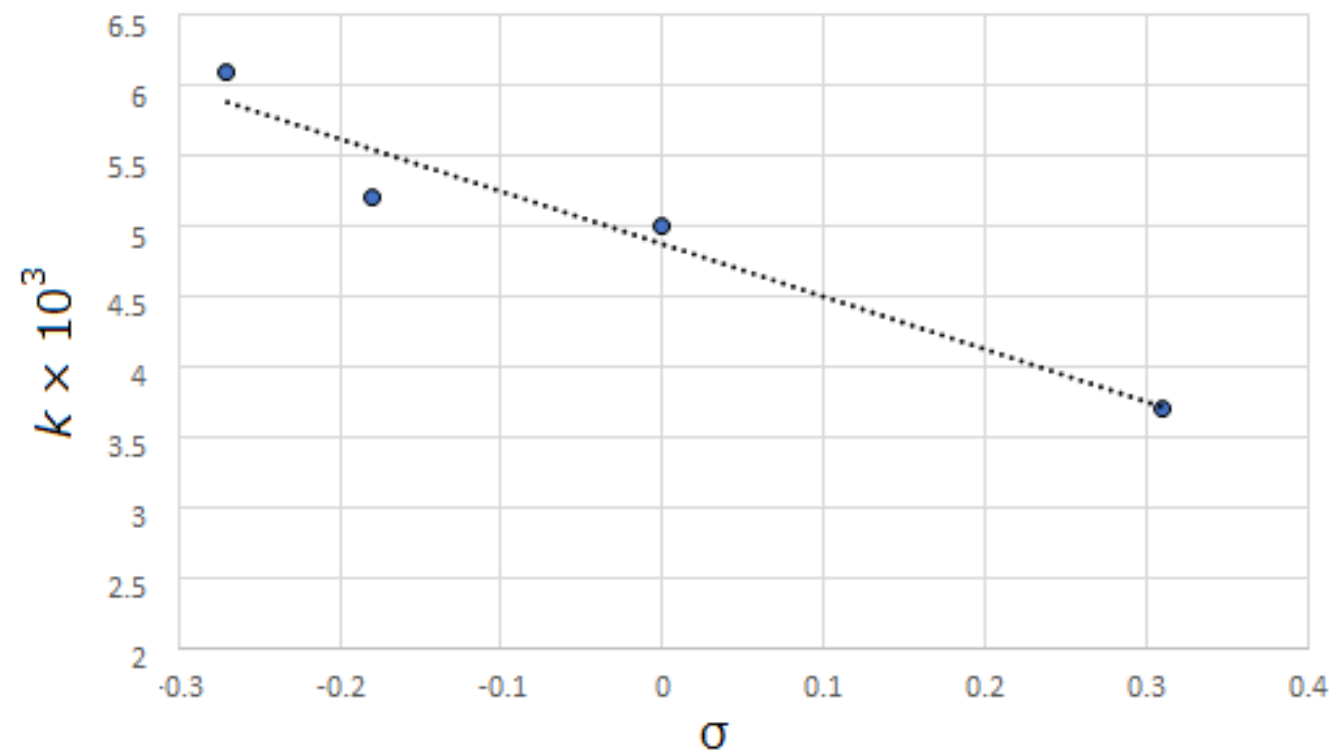

Figure 1. The relationship between the Hammett's substituent constant $(\sigma)$ and the reaction rate constant $(k)$

\subsection{3 (2,4,6-Trimethylbenzoyl)Ferrocene}

(2,4,6-Trimethylbenzoyl)ferrocene showed the fastest reaction rate amongst all the aroylferrocenes. This would be due to the electron-donating effect of the methyl group. Furthermore, the twisting effect caused by the methyl groups at the 2,6-positions would be also affecting the outcome.

\subsection{Alkanoylferrocenes and Aroylferrocenes}

Oxidative decomposition of aroylferrocenes was faster than that of linear alkanoylferrocenes. In terms of steric hindrance, aroylferrocenes are less susceptible than linear alkanoylferrocenes towards the attack by $\mathrm{Fe}^{3+}$ due to the bulkiness and twist of the benzene ring of the arylcarbonyl groups. Conversely, in terms of the electronic factors, the electron-withdrawing effect on ferrocene by the carbonyl group will be alleviated by the electron-donating effect of the substituent on the benzene ring. As the electron-donating effect exceeded the steric effect, it was inferred that the reaction rate was faster.

\section{Conclusion}

The oxidative decomposition reaction of some alkanoyl- and aroylferrocenes by iron(III) chloride was investigated. The rate of decomposition of alkanoylferrocenes was strongly influenced by the steric effect of the substituent. The reactivity of aroylferrocenes was lower than that of alkanoylferrocenes, which would be due to the electron-donating effect of the substituent on the benzene ring. Furthermore, the rate of decomposition of aroylferrocene was influenced by the magnitude of twist between the phenyl and cyclopentadienyl groups.

\section{References}

Bahadori, L., Abdul, M. N. S., Chakrabarti, M. H., Hashim, M. A., Mjalli, F. S., Al Nashef, I. M., ... Low, C. T. J. (2013). The electrochemical behaviour of ferrocene in deep eutectic solvents based on quaternary ammonium and phosphonium salts. Phys. Chem. Chem. Phys., 15(5), 1707-1714. https://doi.org/10.1039/C2CP43077K

Hayashi, T., \& Okada, Y. (1995). Steric effect of $t$-butyl groups and solvent effect on the oxidation reaction of t-butylferrocenes. Bull. Chem. Soc. Jap., 64(2), 485-489. https://doi.org/10.1246/bcsj.64.485

Hayashi, T., Okada, Y., \& Hukuchi, T. (1994). The Oxidative Decomposition Reaction of Acylferrocenes under Acidic Conditions. Nippon Kagaku Kaishi, (4), 340-344. https://doi.org/10.1246/nikkashi.1994.340

Hosseini, A., Collman, J. P., Devadoss, A., Williams, G. Y., Barile, C. J., \& Eberspacher, T. A. (2010). Ferrocene Embedded in an Electrode-Supported Hybrid Lipid Bilayer Membrane: A Model System for Electrocatalysis in a 
Biomimetic Environment. Langmuir, 26(22), 17674-17678. https://doi.org/10.1021/la1029118

Jaffe, H. H. (1953). A Reexamination of the Hammett Equation. Chem. Rev. 53(2), 191-261. https://doi.org/10.1021/cr60165a003

Kokesh, F. C., \& Hall, R. E. (1975). Reexamination of the equilibrium addition of bisulfite and sulfite ions to benzaldehyde. J. Org. Chem., 4O(11), 1632-1636. https://doi.org/10.1021/jo00899a024

Muther, K., Frohlich, R., Muck-Lichtenfeld, C., Grimme, S., \& Oestreich, M. (2011). A Unique Transition Metal-Stabilized Silicon Cation. J. Am. Chem. Soc., 133(32), 12442-12444. https://doi.org/10.1021/ja205538t

Okada, Y., \& Hayashi, T. (1989). Oxidation Reaction of (o-substituted phenyl)ferrocenes. Bull. Chem. Soc. Jap., 62(1), 114-118. https://doi.org/10.1246/bcsj.62.114

Okada, Y., Nakagawa, T., \& Hayashi, T. (2001). Oxidation reaction of (2,6-disubstituted phenyl)ferrocenes. Inorg. Chim. Acta, 312(1-2), 197-200. https://doi.org/10.1016/S0020-1693(00)00306-6

Palmer, R. H., Liu, J., Kung, C. W., Hod, I., Farha, O. K., \& Hupp, J. T. (2018). Electroactive Ferrocene at or near the Surface of Metal-Organic Framework UiO-66. Langmuir, 34(16), 4707-4714. https://doi.org/10.1021/acs.langmuir.7b03846

Zora, M., Kokturk, M., \& Eralp, T. (2006). Synthesis of 2-ferrocenylidene-4-cyclopentene-1,3-diones. Tetrahedron, 62(44), 10344-10351. https://doi.org/10.1016/j.tet.2006.08.078

Zora, M., Tumay, T. A., \& Bueyuekguengoer, B. (2007). Coupling of cyclopropylcarbene-chromium complex with ferrocenyl alkynes: synthesis of 5-ferrocenyl-5-hydroxy-2-cyclopentenones and 4-ferrocenyl-4cyclopentene-1,3-diones. Tetrahedron, 63(19), 4018-4026. https://doi.org/10.1016/j.tet.2007.03.001

\section{Copyrights}

Copyright for this article is retained by the author(s), with first publication rights granted to the journal.

This is an open-access article distributed under the terms and conditions of the Creative Commons Attribution license (http://creativecommons.org/licenses/by/4.0/). 